\title{
Excimer laser coronary angioplasty in the Netherlands: Preamble for a randomized study
}

\author{
Sipke Strikwerda, MD, a Jacques J. Koolen, MD, ${ }^{b}$ Pim J. de Feyter, MD, ${ }^{a}$ \\ Rene L.H. Sprangers, MD, ${ }^{\mathrm{c}}$ Jan G. P. Tijssen, PhD, ${ }^{\mathrm{d}}$ and Patrick W. Serruys, MD ${ }^{\mathrm{a}}$ \\ Rotterdam, The Netherlands
}

Excimer laser coronary angioplasty (ELCA) is the newest modality in the armamentarium of the interventional cardiologist for the percutaneous recanalization of coronary artery stenoses. Since the introduction of coronary balloon angioplasty (PTCA) in 1977 by the late Andreas Grüntzig, ${ }^{1}$ balloon catheter systems have improved considerably. In the following years, the indication for PTCA gradually expanded to include patients with multivessel disease and complex coronary obstructions. More recently, a variety of new nonballoon devices have been introduced $^{2}$ to specifically address coronary lesions with a morphology not ideal for conventional PTCA. Of these new techniques, directional and rotational atherectomy and ELCA bring about debulking of coronary atherosclerotic tissue mass. Removal of atherosclerotic plaque by resection or ablation is thought to potentially increase immediate success rates, reduce acute complication rates, and improve long-term results in the percutaneous treatment of complex coronary lesions.

Since the first patient with coronary artery disease was treated with ELCA in August $1988,{ }^{3}$ experience with this technique has grown rapidly. Early and late results of ELCA with a pulsed $\mathrm{XeCl}$ excimer laser at $308 \mathrm{~nm}$ in combination with multiple-fiber over-thewire laser catheters of various diameters developed by Advanced Interventional Systems (AIS) (Irvine, Calif.), ${ }^{4-6}$ Spectranetics (Colorado Springs, Colo.), ${ }^{7,8}$

\footnotetext{
From aDepartment of Cardiology, Catheterization Laboratory, Thorax center, University Hospital Dijkzigt, Erasmus University, Rotterdam; and ${ }^{b}$ Department of Cardiology, 'Laser Center, and dDepartment of Clinical Epidemiology, Academic Medical Center, Amsterdam, The Netherlands. Received for publication Apr. 3, 1992; accepted Sept. 3, 1992.

Reprint requests: Sipke Strikwerda, MD, Catheterization Laboratory, Thoraxcenter, Bd 414, University Hospital Dijkzigt, Erasmus University, P.O. Box 1738, 3000 DR Rotterdam, The Netherlands.

AM HEAKT J 1993;125:838-847.

Copyright "' 1993 by Mosby-Year Book, Inc.

$0002-8703 / 93 / \$ 1.00+.10 \quad \mathbf{4} / \mathbf{1} / \mathbf{4 3 4 6 0}$
}

and Technolas (Grafelfing, Germany) ${ }^{9}$ have been reported. Recently, multicenter results that involved more than 2100 patients and 2500 lesions treated with ELCA with these respective laser systems were presented. ${ }^{10-12}$ The procedural success rate in the ELCA registry of AIS, which includes 1570 patients, was as high as $89 \%,{ }^{10}$ and clinical success in a registry of Spectranetics laser procedures (487 patients) was achieved in $85 \% .11$ The six-month restenosis rate after ELCA, however, does not appear to be lower than after balloon PTCA alone. $6,8,9,13$

The purpose of this article is to present the first results of ELCA in the Netherlands with regard to immediate efficacy and safety of use of the laser system that was developed by AIS. These results are then discussed in view of the initial experience of other centers and recent data from multicenter registries of ELCA procedures. Finally, the rationale and design of a randomized study of ELCA versus conventional PTCA is described.

\section{METHODOLOGY}

Since the introduction of ELCA in the Netherlands in February 1990 until September 1991, 71 patients with 72 lesions were selected to undergo ELCA with the laser system that was developed by AIS. The initial results obtained at the Academic Medical Center in Amsterdam until December 1990 (Fig. 1, period I) has recently been published. ${ }^{14}$ The Thoraxcenter in Rotterdam started performing ELCA with the AIS laser in December 1990. The joint experience in both centers from December 1990 until September 1991 (Fig. 1, period $I I$ ) is reported here.

Patients. In period II 1009 patients underwent PTCA in the two centers; of these, 53 patients with 53 lesions were selected for ELCA on the basis of previous experience with ELCA by our group and other groups. All patients had symptomatic coronary artery disease and/or objective evidence of myocardial ischemia and had been accepted for a percuta- 


\section{EXCIMER LASER CORONARY ANGIOPLASTY (ELCA) \\ DUTCH EXPERIENCE WITH THE AIS SYSTEM}

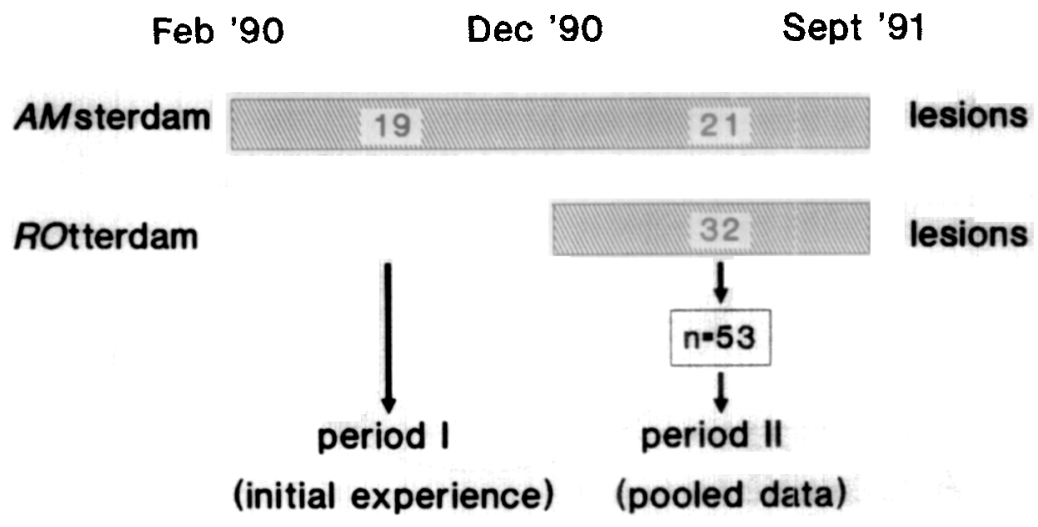

Fig. 1. Overview of past experience with ELCA in the Netherlands with the use of the laser system developed by Advanced Interventional Systems, Inc. Results of ELCA from December 1990 to September 1991 (period II; 53 lesions in 53 patients) are described.

neous transluminal coronary intervention. The male to female ratio was $40: 13$, and the age (mean \pm SD) was $59 \pm 10$ years with a range of 40 to 77 years. Most patients ( 45 of $53 ; 85 \%$ ) were in New York Heart Association (NYHA) functional class III or IV for angina pectoris (Fig. 2, A). Twenty-five lesions were located in the distribution of the left anterior descending coronary artery, 17 in the right coronary artery, and 9 lesions were located in the left circumflex coronary artery. Two patients underwent ELCA for a significant stenosis in the main stem of the left coronary artery, which was protected by an aortacoronary bypass graft. Forty-five of the 53 lesions ( $85 \%$ ) were classified as type $\mathrm{B}$ or $\mathrm{C}$ according to the joint American College of Cardiology/American Heart Association (ACC/AHA) Task Force criteria ${ }^{15}$ (Fig, 2, $B)$. With growing experience, more patients with type $\mathrm{B}$ and $\mathrm{C}$ lesions were included in the series.

Laser system. The laser system used consisted of an $\mathrm{XeCl}$ excimer laser (Advanced Interventional Systems, Inc., Irvine, Calif.) emitting light pulses at 308 $\mathrm{nm}$ in the ultraviolet portion of the electromagnetic spectrum with a pulse duration of about $200 \mathrm{~ns}$ and a repetition rate of $20 \mathrm{~Hz}$. Multifiber over-the-wire laser catheters of $1.3,1.6$, and $2.0 \mathrm{~mm}$ diameter were coupled to the laser, and fluence at the catheter tip was set at levels of 45 to $60 \mathrm{~mJ} / \mathrm{mm}^{2}$.

Procedure. All patients were pretreated with a calcium-channel entry blocker, and aspirin was either continued orally or given intravenously at the begin- ning of the procedure. After insertion of arterial and venous introducer sheaths into the femoral vessels, a heparin bolus of $10.000 \mathrm{IU}$ was administered. Additional doses of 5.000 IU heparin were given in order to achieve an activated clotting time of at least 400 seconds for the duration of the procedure. Standard coronary angioplasty guide catheters (Schneider, Inc., Minneapolis, Minn.) of $9 \mathrm{~F}$ for the $1.3 \mathrm{~mm}$ laser catheter and $9 \mathrm{~F}$ superflow for 1.6 and $2.0 \mathrm{~mm}$ laser catheters were used. Intracoronary nitroglycerin was given to reduce vasomotor tone, and contrast arteriography was performed in at least two projections (orthogonal if possible).

After passage of a 0.018 inch guide wire across the stenosis into the distal part of the vessel under fluoroscopic control, fluence at the laser catheter tip was calibrated, and the catheter was advanced over the guide wire until its tip was just proximal to the lesion. The laser was then activated for 2 to 3 seconds, and the fiberoptic catheter was slowly advanced over the guide wire without forceful pushing. During laser activation, the guide wire was kept under slight tension or slowly retracted. Each 2- to 3-second pulse train was followed by a pause of 3 to 5 seconds with repositioning of the guide wire into the most distal part of the vessel. In all but two cases in which the lesion was passed twice, only one pass with a laser catheter was performed through the lesion, after which a control angiogram was made. If the residual stenosis was more than $50 \%$, the lesion was passed with a larger 

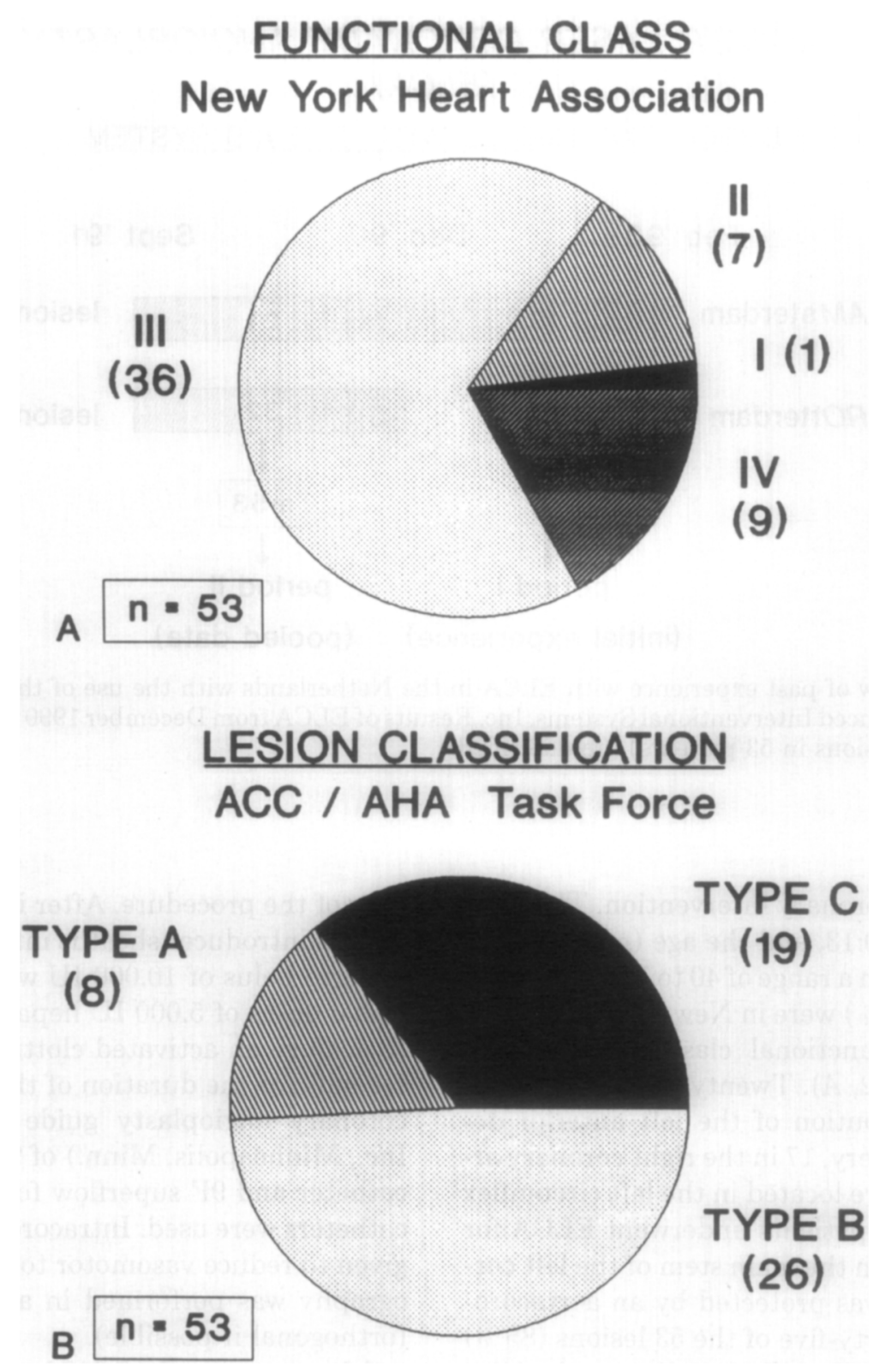

Fig. 2. A, Distribution of severity of angina pectoris according to New York Heart Association functional classification and; B, distribution of coronary lesion complexity according to ACC/AHA Task Force criteria in 53 patients selected to undergo ELCA.

diameter laser catheter or adjunctive balloon PTCA was performed. When the result was considered satisfactory (i.e., a diameter stenosis of less than $50 \%$ on visual inspection), final control angiography was performed in multiple projections after intracoronary administration of nitroglycerin.

After ELCA, the patients were monitored for 24 hours and 12-lead ECGs and cardiac enzyme levels were obtained twice a day. Six hours after the procedure, the sheaths were pulled out. After recanalization of a total or subtotal occlusion, however, the pa- tient was maintained on a heparin drip until the next morning; then heparin was discontinued and the sheaths were removed. The specific post-ELCA drug regimen consisted of aspirin for 6 months after the procedure.

Definition of success. Laser success was prospectively defined as a more than $20 \%$ reduction in diameter stenosis after ELCA alone as assessed by visual analysis of the angiogram. Procedural success was defined as a less than $50 \%$ residual stenosis on visual assessment at the end of the procedure, whether 
achieved by ELCA alone or after adjunctive balloon PTCA. Clinical success was defined as procedural success without death, nonfatal myocardial infarction, coronary artery bypass grafting (CABG), or repeat PTCA during the same hospitalization period as the laser procedure. Myocardial infarction was thought to be present when serum creatine kinase rose over twice the normal upper limit of our laboratory, along with a typical elevation of the $\mathrm{MB}$ fraction.

Quantitative coronary angiography. Quantitative coronary angiography was performed on 31 patients who were actually undergoing ELCA in the Thoraxcenter. Coronary angiograms before ELCA, after ELCA, and, if applicable, after adjunctive balloon PTCA $(n=25)$ were analyzed quantitatively with the computer-assisted Cardiovascular Angiography Analysis System (Pie Medical, Maastricht, The Netherlands), which has previously been described in detail. ${ }^{16}$ In brief, an optically magnified portion of a selected 35 Inm cine frame encompassing the segment of interest is converted into video format by means of a cinevideo converter. The contours of the vessel segment are detected automatically and corrected for pincushion distortion, which is caused by the image intensifier. The minimal luminal diameter of the stenotic segment is determined in absolute millimeters by using the guide catheter as a scaling device. A computer estimation of the original dimension of the artery at the site of the obstruction is used to define the interpolated reference diameter. The percent diameter stenosis can then be calculated. Minimal luminal diameters, reference diameters, and percent diameter stenoses were obtained by analysis of the artery in at least two matched views, orthogonal if possible, and averaged.

Statistical analysis. Results of quantitative coronary angiography are presented as mean values \pm 1 SD. Comparison between groups (before ELCA, after ELCA, and after PTCA) was performed with paired and unpaired two-tailed Student's $t$ tests. A $p$ value of $<0.05$ was considered to indicate a significant difference.

\section{OBSERVATIONS}

Overall results by visual assessment. Of the 53 patients who were selected to undergo F.LCA in both centers during period II (Fig. 1), 50 underwent actual treatment with the AIS laser system (Fig. 3, intention-to-treat principle). In two patients an intimal dissection occurred during guide wire manipulation after which ELCA was cancelled; one patient underwent subsequent successful balloon PTCA, and the other patient was referred for elective $\mathrm{CABG}$.
'The third failure was caused by a technical problem with the laser. Immediate laser success was achieved in 41 of the 50 patients who underwent ELCA. In two patients the laser catheter did not cross the lesion; in three other patients an acute occlusion occurred after laser ablation, and in the remaining four patients diameter stenosis was considered as not being reduced by at least $20 \%$ after ELCA alone on visual assessment. Thirty-seven of 50 patients $(74 \%)$ underwent adjunctive balloon PTCA. After PTCA coronary occlusion occurred in two more patients and was successfully treated by additional balloon dilatations.

Procedural success was achieved in 48 patients. One patient had a "sustained" coronary occlusion after ELCA despite multiple balloon dilatations, stent implantation, and intracoronary thrombolysis. After an autoperfusion balloon catheter was positioned and coronary flow was adequately restored, the patient was referred for emergency CABG. In another patient a distal coronary occlusion developed after dissection of the treated segment, and the patient had a small myocardial infarction. After completion of the procedure (ELCA with or without adjunctive PTCA) and removal of the guide catheter, four patients had symptoms and signs of myocardial ischemia within 24 hours of the initial procedure, which necessitated coronary angiography and repeat intervention. In two patients a total occlusion was found to result in a myocardial infarction in both, despite successful balloon PTCA in one patient. Two other patients underwent successful repeat PTCA because of early recurrence of the previously treated stenosis that caused angina pectoris. Overall, clinical success was achieved in 44 patients (83\%). In Fig. 4, success rates are depicted graphically.

Complications. Procedural complications, that is those that occurred before removal of the guide catheter, are summarized in Table I. Intimal dissection was primarily associated with adjunctive PTCA after ELCA and was limited to types $A$ and $B$ according to the classification of Dorros et al. ${ }^{17} \mathrm{~A}$ transient occlusion after ELCA in four patients could be resolved by subsequent balloon PTCA. No coronary perforations (i.e., extravasation of contrast medium) were noted. Clinical complications that occurred during the hospitalization period are listed in Table II and are mutually exclusive; that is, only the most severe event in the ranking order (death, nonfatal myocardial infarction, emergency $\mathrm{CABG}$, and repeat $\mathrm{P} T \mathrm{CA}$ ) is counted in an individual patient.

Quantitative coronary angiography. The immediate efficacy of ELCA ( $n=31$ lesions) with adjunctive PTCA ( $n=25$ lesions) as assessed by quantitative 


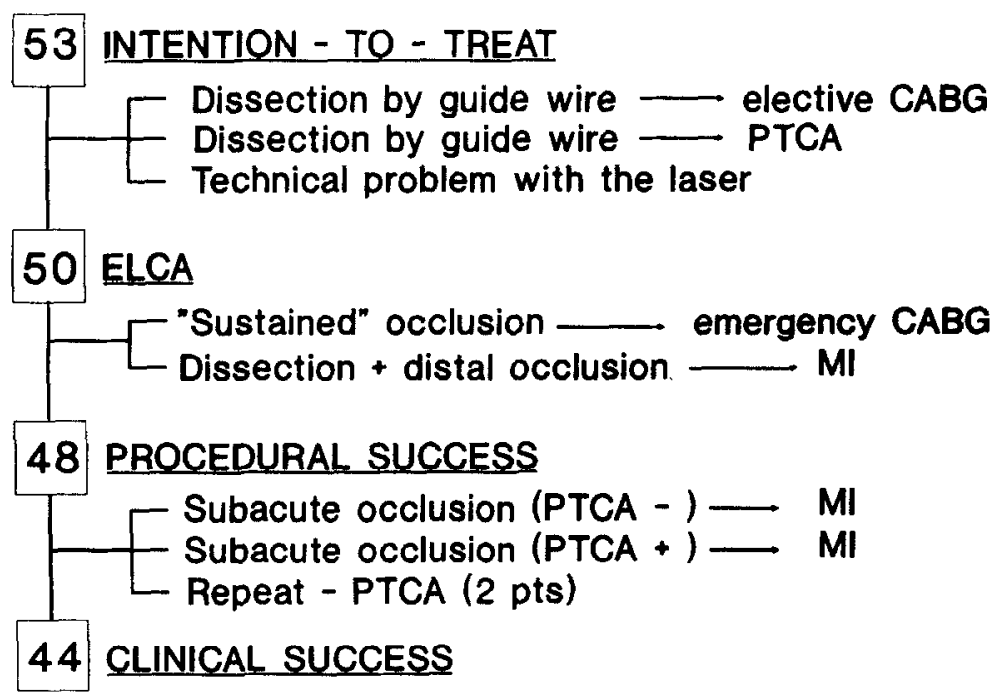

Fig. 3. Flow chart showing procedural and clinical complications in 53 patients ( $p t s$ ) selected for ELCA. For definitions of success, see text. $C A B G$, Coronary artery bypass grafting; $M I$, myocardial infarction; $P T C A$, percutaneous transluminal coronary balloon angioplasty.

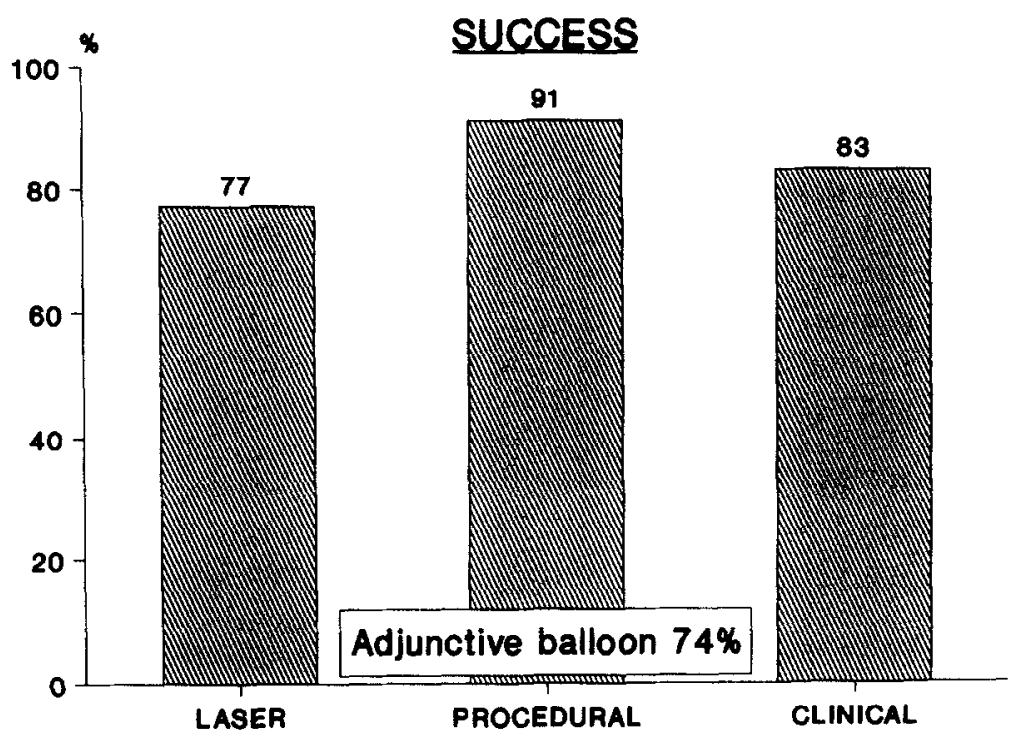

Fig. 4. Success rates in 53 patients (intention-to-treat analysis) selected to undergo ELCA on the basis of visual assessment of the angiogram with categorical cutoff criteria. For definitions of success, see text. Thirty-seven patients ( $74 \%$ ) had adjunctive balloon angioplasty (PTCA) after ELCA.

coronary angiography is shown in Figs. 5 and 6 . Preprocedural minimal luminal diameter was $0.77 \pm$ $0.41 \mathrm{~mm}$. ELCA significantly improved minimal lumen diameter to $1.24 \pm 0.25 \mathrm{~mm}(p<0.0001)$, and with PTCA, it further increased to $1.67 \pm 0.29 \mathrm{~mm}$ $(p<0.0001)$. Reference diameter did not change significantly. Thus percent diameter stenosis was reduced from $69 \% \pm 16 \%$ to $50 \% \pm 12 \%(p<0.0001)$ after ELCA, and further to $37 \% \pm 7 \%(p<0.0001)$ after adjunctive PTCA.

\section{COMMENTS}

Since the introduction of ELCA in the clinical setting, profound modifications were brought into catheter construction, treatment protocol, and patient selection. The first clinical laser catheter of AIS contained $12200 \mu \mathrm{m}$ tipped optical fibers and came in only one diameter of $1.6 \mathrm{~mm} .{ }^{4}$ At present, catheters are available in multiple sizes that range from 1.3 to $2.4 \mathrm{~mm}$ and contain hundreds of $50 \mu \mathrm{m}$ fibers. The incorporation of a greater number of optical fibers of 


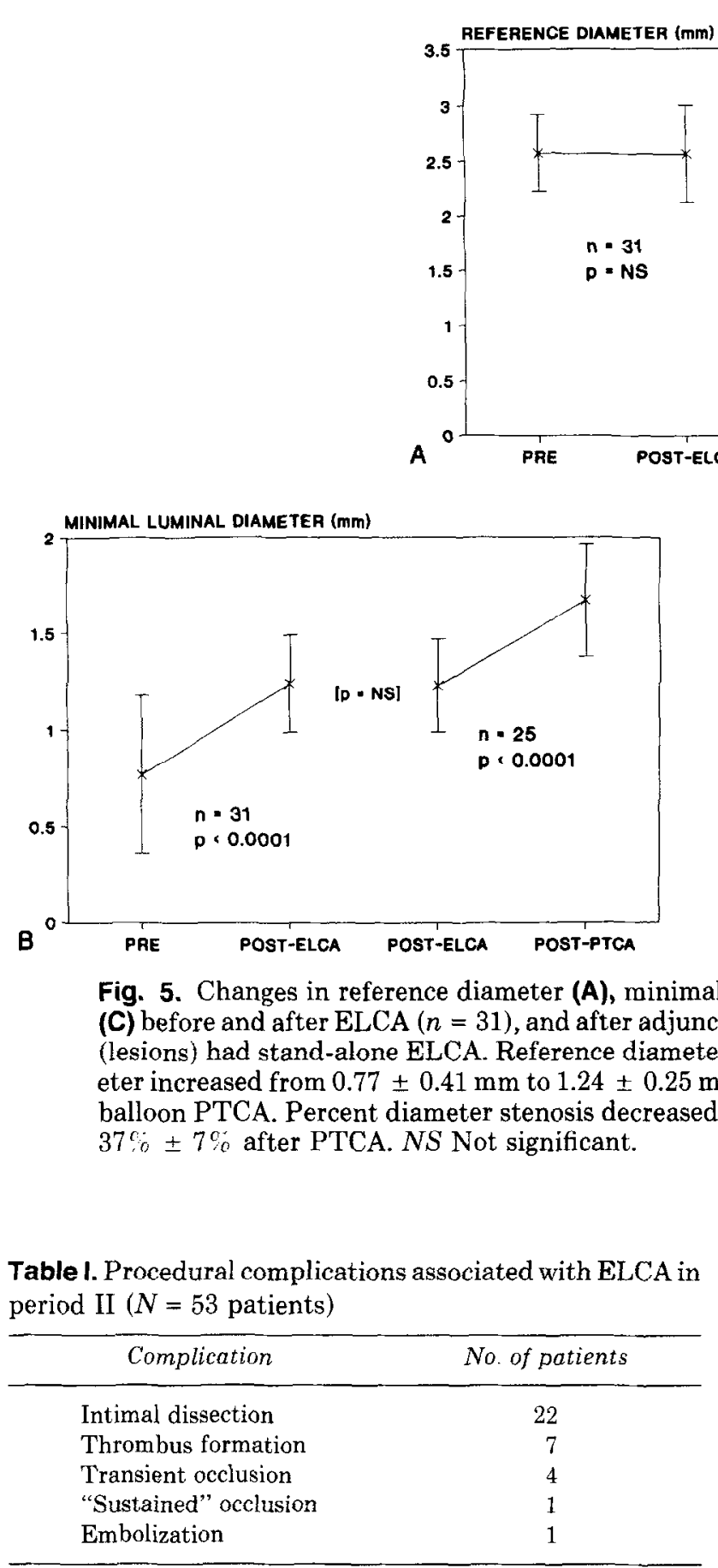

smaller diameter has increased catheter flexibility and also reduced the area at the tip of the catheter that is not available for laser ablation (the so-called "dead space"). The dead space between the individual fibers at the tip of the catheters used in this study, however, still averaged around $80 \%$ of the total tip area (T. Goldenberg, personal communication). A reduction in dead space should reduce the mechanical dilating or "dottering" effect of a laser catheter
Table II. Clinical complications associated with ELCA in period II ( $N=53$ patients)

\begin{tabular}{lc}
\hline Complication & No. of patients \\
\hline Death & $0(0 \%)$ \\
Nonfatal MI & $3(6 \%)$ \\
Emergency CABG & $1(2 \%)$ \\
Repeat PTCA & $2(4 \%)$ \\
\hline
\end{tabular}

$M I$, Myocardial infarction; $C A B G$, coronary artery bypass grafting; $P T C A$ percutaneous transluminal coronary angioplasty.

and iucrease the efficiency of ablation. Also for this reason, fluence levels emitted from the catheter have been increased from about $40 \mathrm{~mJ} / \mathrm{mm}^{2}$ in initial ELCA procedures to maximum fluences of around 60 $\mathrm{mJ} / \mathrm{mm}^{2}, 5,6$ which is well above the ablation threshold of noncalcified plaque and probably above the threshold for calcified tissue. Thresholds and efficiency of ablation of calcified plaque by $\mathrm{XeCl}$ excimer 


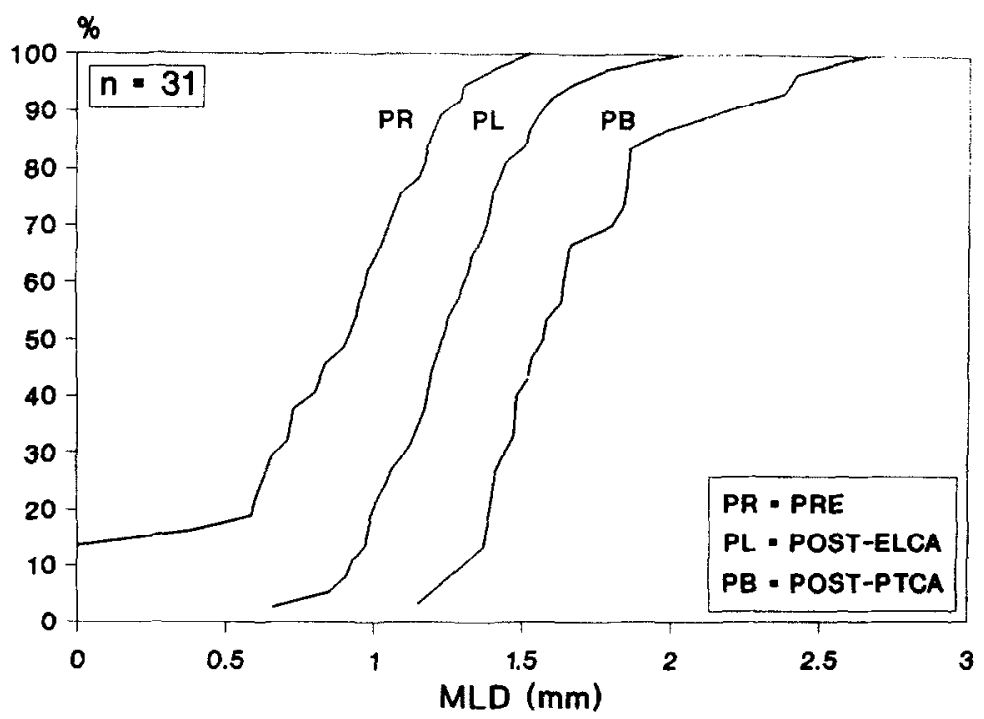

Fig. 6. Cumulative frequency of immediate results of ELCA and adjunctive balloon angioplasty (PTCA) in 31 and 25 lesions, respectively, as assessed by quantitative coronary angiography. $M L D$, Minimal luminal diameter.

laser radiation have been experimentally determined $^{18,19}$ and depend on the laser pulse duration, the medium in which tissue ablation takes place (air, saline solution, blood) and the degree of plaque calcification. Currently, it is well recognized that optimal debulking of atherosclerotic tissue mass is a prerequisite for a good procedural result with ELCA. ${ }^{13,20,21}$

Subacute closure of the treated vessel occurs more often after ELCA than after conventional PTCA and may result from insufficient tissue ablation, ${ }^{20,21} \mathrm{re}$ versible coronary spasm, ${ }^{22}$ and/or thrombosis. Liberal use of intracoronary nitroglycerin is advocated, and a strict antiplatelet and anticoagulation protocol has been implemented. In addition to aspirin, adequate doses of heparin are given to keep the activated clotting time above 400 seconds for the duration of the procedure. Some centers maintain their patients on an overnight heparin drip after ELCA in order to further reduce thrombotic complications in the subacute phase. Moreover, adjunctive balloon PTCA is now performed in approximately two thirds of patients who undergo $\mathrm{ELCA}^{10}$ to optimize the final result of the intervention with a minimum of residual stenosis.

Finally, case selection for ELCA has undergone considerable change. After it was recognized that ELCA did not appear to have an advantage over PTCA in uncomplicated and discrete coronary lesions with respect to immediate and long-term outcome, there has been a trend toward treating coronary lesions that are not ideal for conventional
PTCA, particularly ostial lesions, tubular and diffuse disease, saphenous vein grafts, and chronic total occlusions. On the basis of this development, one may anticipate a downward shift in immediate success rates as would be expected for PTCA. Data from the AIS $^{10}$ and Spectranetics ${ }^{11}$ registries, however, show that lesion length and complexity do not seem to influence results. Also, the frequency of major complications (CABG, myocardial infarction, death) did not differ significantly between lesions with simple or complex angiographic morphology. ${ }^{10,11}$

Initial immediate results obtained in the first 50 to 60 patients who were treated with an $\mathrm{XeCl}$ excimer laser have been reported previously. Litvack et al. ${ }^{4}$ achieved $84 \%$ laser success and $93 \%$ procedural success in the first 55 patients who underwent ELCA with the AIS system in a prospective, nonrandomized, multicenter trial. Sanborn et al. ${ }^{7}$ reported a $75 \%$ laser success rate and a $100 \%$ procedural success rate in the first 50 patients who were treated with the Spectranetics laser. Karsch et al. ${ }^{9}$ reported a $70 \%$ laser success rate and an $88 \%$ procedural success rate in the first 60 patients who were treated with the Technolas system. Laser success was somewhat lower in the latter patient series, possibly as a result of catheter technology and/or subthreshold fluences for laser ablation of atherosclerotic tissue used in this protocol. It is remarkable that, despite considerable modifications in laser catheter design and procedural protocol, immediate results of ELCA have not improved since the first patients were treated. This implies that initial success rates claimed by pioneering 
investigators should at least be viewed with healthy skepticism. After 3 years of technical developments and increasing operator experience, procedural and clinical successes in the large multicenter registries which now include over 2000 patients, appear to be even somewhat lower than in the beginning, namely $89 \%$ and $85 \%$, respectively. ${ }^{10,11}$ This observation poses questions about the validity of data bases set up by companies that sponsor laser systems. ${ }^{23}$ One can argue, however, that superior results of highly experienced investigators may be negated by centers that are starting to perform ELCA and initially provide unfavorable data to the registry because of their learning curve. An important weakness of the current registries is that ELCA procedures are assessed by visual, and hence, nonobjective analysis of the angiogram with arbitrary, categorical criteria for success.

Cook et al. ${ }^{5}$ recently reported the experience with ELCA in the first 100 patients who were treated at the Cedars-Sinai Medical Center in Los Angeles with the AIS system between July 1988 and March 1990, when new laser catheters of $1.3,1.6$, and $2.0 \mathrm{~mm}$ in diameter became available. Coronary angiograms were analyzed with a modification of the method described by Brown et al., ${ }^{24}$ a computer-assisted visual analysis in which luminal contours are hand-traced. Immediate laser success was thus achieved in $84 \%$ and procedural success in $94 \%$ of patients. The ACC/AHA Task Force classification of coronary lesion morphology ${ }^{15}$ was used as a basis to compare the results of ELCA with the anticipated initial success rates of conventional PTCA. In type $A, B$, and $\mathrm{C}$ lesions immediate laser successes were $83 \%, 88^{\circ}$, and $85^{\circ}$, respectively, versus $92 \%, 81 \%$, and $61 \%$ for balloon P'TCA as reported by Eillis et al. ${ }^{25}$ In addition, results were independent of lesion length, a separate ACC/AHA Task Force classification characteristic. For stenoses and total occlusions shorter than $10 \mathrm{~mm}$, of 10 to $20 \mathrm{~mm}$, and longer than $20 \mathrm{~mm}$, laser success rates were $88 \%, 82 \%$, and $80 \%$, respectively, which were not significantly different. Complication rates with ELCA in type $B$ and C lesions ( $2 \%$ and $0 \%$, respectively) also compared favorably with PTCA ( $6 \%$ and $21 \%$, respectively). ${ }^{25}$ It can be concluded from this study ${ }^{5}$ that ELCA may be a useful therapy with potential advantages over standard balloon PTCA in lesions with certain type B and C characteristics.

Limitations of the study by Cook et al. ${ }^{5}$ are the absence of an objective quantitative analysis technique for coronary angiograms, the presence of selection bias, and lack of randomization. Patients were selected for ELCA on the basis of previous experience with laser and balloon angioplasty. Thus many pa- tient and lesion characteristics may have been more "ideal" for ELCA as opposed to PTCA. Moreover, immediate results of ELCA were compared with data from registries of conventional PTCA ${ }^{15,25}$ with the use of morphologic criteria that were originally developed for balloon angioplasty. The definition of a type $\mathrm{C}$ lesion, for example, contains a number of different morphologic criteria, which range from excessive vessel tortuosity to chronic total occlusion. Two type $\mathrm{C}$ lesions are not the same, and lesion characteristics are likely to not have been similar in the ELCA group and PTCA registry patients. In addition, definitions of procedural complications, such as intimal dissection, may not have been the same, which could lead to spurious findings. Careful description and comparison of patient and procedural characteristics, as well as definitions, are necessary for a meaningful comparison between ELCA and PTCA registry results. ${ }^{26}$ Ideally, a prospective, randomized trial of ELCA versus PTCA in which patient and lesion characteristics are balanced should be undertaken to assess the relative benefits of these techniques in the treatment of a specific and well-defined coronary pathologic condition. In this setting, automated quantitative coronary angiography is required to objectively determine whether "debulking" of an atherosclerotic lesion by ELCA would result in superior immediate and late outcomes as compared with P'TCA alone.

Our experience (Fig. 1, period II) with ELCA as described here relates to a population of 53 patients with slightly more severe and complex coronary artery disease than the initial patient cohort treated by Cook et al., ${ }^{5}$ as judged by angina pectoris New York Heart Association functional class (class III and IV, 85 vs $74 \%$ and ACC/AHA Task Force coronary lesion classification (types $\mathrm{B}$ and $\mathrm{C}, 85 \%$ vs $72 \%$ ). In our group no patients were treated with ELCA for saphenous vein graft disease, possibly an "ideal" indication for this intervention. ${ }^{5}$ When we used similar catheter equipment and medical protocol, we found in our patient group an immediate laser success rate of 775 , a procedural success rate of $91 \%$, and a clinical success rate of $83 \%$ by visual assessment of the angiogram. These figures fall $5 \%$ to $10 \%$ short compared with the immediate outcomes reported by the Cedars-Sinai group ${ }^{5}$ and in the ELCA registry of AIS. ${ }^{10}$ Important procedural differences include the application of only one pass with a particular diameter laser catheter in our protocol, whereas multiple (one to five) passes were made through the lesion by Cook et al. ${ }^{5}$ Adjunctive PTCA, on the other hand, was performed in $74 \%$ of our patients compared with $47^{\circ}$, of Cedars-Sinai patients. ${ }^{5}$ 
This may explain the relatively frequent occurrence of intimal dissection in our experience, which was primarily associated with adjunctive balloon dilatation after ELCA. However, the visual interpretation of cine angiograms for the presence of angiographic success and/or complications is prone to subjectivity, depends on the quality of the image, and may suffer from different definitions used. When the criteria for visual assessment of ELCA success are applied to individual quantitative coronary angiographic measurements of pre-ELCA, post-ELCA, and post-PTCA angiograms, laser, procedural, and clinical success rates in the present population are $44 \%, 84 \%$, and $75 \mathrm{c}$, respectively. Thus there is considerable discrepancy between visual and quantitatively determined success rates, particularly after ELCA alone, when arbitrary, categorical cutoff criteria are used. This underscores the importance of a continuous ap proach for the evaluation of ELCA procedures (i.e., automated quantitative coronary angiographic analysis). Consequently, new criteria that are based on absolute measurements of coronary luminal dimensions should be designed or developed to assess results of ELCA in an objective manner.

The AMRO study. In September 1991 the Academic Medical Center (Amsterdam) and the Thoraxcenter (Rotterdam) initiated an ongoing cooperative ran domized study of the efficacy of ELCA versus balloon PTCA in the treatment of long ( $\geq 10 \mathrm{~mm}$ ) coronary stenoses or occlusions.

Patient selection. The target population includes patients with stable angina pectoris and objective signs of myocardial ischemia who are scheduled to undergo a percutaneous intervention for a coronary stenosis $(>50 \%$ diameter reduction) or occlusion of $10 \mathrm{~mm}$ or longer as visually assessed on the diagnostic angiogram. Clinical exclusion criteria are unstable angina, evolving or recent (within the past 2 weeks) myocardial infarction, and contraindication for emergency CABG. A life expectancy of less than 1 year and factors that make clinical or angiographic follow-up unlikely also form exclusion criteria. Angiographic exclusion criteria are intended angioplasty of a venous coronary bypass graft, unprotected left main coronary artery disease, extreme tortuosity of the vessel segment to be treated, highly eccentric lesions, bifurcation lesions, intended angioplasty of a lesion with angiographic evidence of thrombus, and total occlusion with a very low chance of crossing by guide wire. A total of 300 patients will be enrolled in 2 years.

Randomization and treatment. After written informed consent is obtained, patients undergo a baseline exercise test including technetium (Tc) $99 \mathrm{~m}$ methoxyisobutyl isonitrile (MIBI) single photon emission computed tomography (SPECT) and are then randomly assigned to one of two treatment groups (PTCA or ELCA). All patients are pretreated with a calcium-channel entry blocker and receive the intervention within 2 days of randomization. Aspirin is given before and for 6 months after the procedure; heparin is given at the beginning and during the procedure to keep the activated clotting time above 400 seconds, and intracoronary nitroglycerin is given during the procedure at the operator's discretion. All patients are maintained on an overnight heparin drip until the morning after the procedure. Until hospital discharge, $20 \mathrm{mg}$ of nifedipine is given three times daily. PTCA is performed with standard technique and modern balloon catheter equipment. The technical details of ELCA are described above and will be in accordance with the latest insights and AIS clinical protocol.

Follow-up. After discharge, patients are seen after 1 and 6 months. If symptoms recur after successful angioplasty, medical therapy is first optimized. Six months after randomization or when symptoms dictate, exercise testing with ${ }^{99 \mathrm{~m}} \mathrm{Tc}$ MIBI SPECT $\mathrm{T}$ and repeat quantitative coronary angiography are performed. During follow-up exercise testing and myocardial perfusion studies, all medication for angina pectoris will be withdrawn if clinical status permits.

End points. Primary clinical end points of the study are the occurrence of any of the following: cardiac death, myocardial infarction, $\mathrm{CABG}$, stent im. plantation, or repeat PTCA after the initial procedure. The primary scintigraphic end point is the extent of myocardial perfusion as assessed by ${ }^{99 \mathrm{~m}} \mathrm{Tc}$ MIBI SPECT at followup. The primary angiographic end point is the minimal luminal diameter at the treated coronary site at 6 months relative to baseline as determined by quantitative analysis with an automated contour detection technique (Cardiovascular Angiography Analysis System), as described above. Secondary end points include patients' functional class for angina pectoris, other quantitative angiographic parameters (percent diameter stenosis, reference diameter, plaque area) at 6 months relative to baseline and evidence of restenosis in the two treatment groups according to the various criteria. Finally, a cost-benefit analysis will be performed.

\section{SUMMARY}

The immediate outcome of ELCA by $\mathrm{XeCl}$ excimer laser radiation is described in 53 patients who were selected to undergo ELCA from December 1990 to September 1991 in two centers that are currently performing ELCA in the Netherlands. Immediate success rates on the basis of visual assessment of the angiogram were as follows. Laser success $(>20$, reduction of diameter stenosis after ELCA alone) was 
observed in $77 \%$ of patients, procedural success $(<50 \%$ residual stenosis after ELCA with or without adjunctive balloon dilatation (P'ICA]) in $91 \%$, and clinical success (procedural success without clinical complications) in $83 \%$ of patients. Quantitative coronary angiography by automated contour detection was performed in 31 patients who underwent ELCA in the Thoraxcenter. The minimal luminal diameter (mean $\pm \mathrm{SD}$ ) of the treated coronary segments increased from $0.77 \pm 0.41 \mathrm{~mm}$ to $1.24 \pm 0.25 \mathrm{~mm}$ after ELCA and further to $1.67 \pm 0.29 \mathrm{~mm}$ after adjunctive PTCA in 25 patients. The present experience is put in perspective of results initially reported by other centers and compared with data from multicenter registries of ELCA. Finally, a short description is given of the design of a prospective, randomized trial of ELCA versus conventional PTCA (AMRO trial).

We thank Eline Montauban van Swijndregt for expert technical assistance and Marjolein Wapenaar for preparation of the manuscript.

\section{REFERENCES}

1. Grüntzig AR, Senning A, Siegenthaler WE. Nonoperative dilatation of coronary-artery stenosis: percutaneous transluminal coronary angioplasty. N Engl J Med 1979;301:61-8.

2. Waller BF. "Crackers, breakers, stretchers, drillers, scrapers, shavers, burners, welders and melters" - the future treatment of atherosclerotic coronary artery disease? A clínical-morphologic assessment. J Am Coll Cardiol 1989;13:969-87.

3. Litvack F, Grundfest W, Eigler N, Tsoi D, Goldenberg T, Laudenslager J, Forrester J. Percutaneous excimer laser coronary angioplasty. Lancet 1989;2:102-3.

4. Litvack F, Eigier NL, Margolis JR, Grundfest WS, Rothbaum D, Linnemeier T, Hestrin LB, Tsoi D, Cook SL, Krauthamer D, Goldenberg T, Laudenslager JR, Segalowitz J, Forrester J. Percutaneous excimer laser coronary angioplasty. Am J Cardiol 1990;66:1027-32.

5. Cook SL, Eigler NL, Shefer A, Goldenberg T, Forrester JS, Litvack F. Percutaneous excimer laser coronary angioplasty of lesions not ideal for ballon angioplasty. Circulation 1991; 84:632-4.3.

6. Margolis JR, Krauthamer D, Litvack F, Rothbaum DA, Untereker WJ, Bresnahan JF, Kent KM, Cummins FE, and the ELCA Registry Investigators. Six month follow-up of excimer laser coronary angioplasty registry patients [Abstract]. J Am Coll Cardiol 1991;17:218A.

7. Sanborn TA, Torre SR, Sharma SK, Hershman RA, Cohen M, Sherman W, Ambrose JA. Percutaneous coronary excimer laser-assisted balloon angioplasty: initial clinical and quantitative angiographic results in 50 patients. J Am Coll Cardiol $1991 ; 17: 94-9$

8. Sanborn TA, Bittl JA, Torre SR. Procedural success, in-hospital events, and follow-up: clinical and angiographic results of percutaneous coronary excimer laser-assisted angioplasty [Abstract]. J Am Coll Cardiol 1991;17:206A.

9. Karsch KR, Haase KK, Voelker W, Baumbach A, Mauser M, Seipel L. Percutaneous coronary excimer laser angioplasty in patients with stable and unstable angina pectoris: acute results and incidence of restenosis during 6-month follow-1up. Circulation 1990;81:1849-59.

0 . Holmes DR, Litvack F, Goldenberg T, Bresnahan JF, Cummins FE, Margolis JR, for the ELCA Investigators. Excimer coronary laser angioplasty (ELCA) registry: lesion length and outcome [Abstract]. Circulation 1991;84(suppl II):II-362.
11. Sanborn TA, Bittl JA, Siegel RM, Kramer BL, Tcheng JE, Power $J$, for the PELCA registry. Lack of effect of lesion severity on clinical success and complication rates with percutaneous excimer laser coronary angioplasty (PELCA) [Abstract]. Circulation 1991;84 (suppl II):II-362.

12. The European Study Group on Coronary Excimer Laser Angioplasty. Initial results of the European multicenter registry on coronary excimer laser angioplasty [Abstract]. Circulation 1991;84(suppl II):II-362.

13. Ghazzal ZMB, Burton ME, Klein JL, Rothbaum DA, Litvack F, King SB III, Tao X, Weintraub WS. Predictors of restenosis following excimer laser: multicenter comprehensive angiographic analysis [Abstract]. Circulation 1991;84(suppl II):II361 .

14. Sprangers RLH, Gijsbers GHM, David GK, Keijzer M, Koolen JJ, van Gemert MJC. Excimer laser coronary angioplasty: inilial experience in Ansterdam. Lasers Med Sci 1991;6:281-7.

15. Ryan TJ, Faxon DP, Gunnar RM, Kennedy JW, King SB III, Loop FD, Peterson KL, Reeves TJ, Williams DO, Winters WL Jr. Guidelines for percutaneous transluminal coronary angioplasty: a report of the American College of Cardiology/American Heart Association Task Force on assessment of diagnostic and therapeutic cardiovascular procedures (Subcommittee on Percutaneous Transluminal Coronary Angioplasty). J Am Coll Cardiol 1988;12:529-45.

16. Reiber JHC. Serruys PW. Quantitative coronary angiography In: Marcus ML, Schelbert HR, Skorton DJ, Wolf GL, eds Cardiac imaging. A companion to Braunwald's heart disease. Philadelphia: WB Saunders, 1991:213-80.

17. Dorros G, Cowley MJ, Simpson J, Bentivoglio LG, Block PC, Bourassa M, Ketre K, Gosselin AJ, Gruntzig AR, Kelsey SF, Kent KM, Mock MB, Mullin SM, Myler RK, Passamani ER, Stertzer SH, Williams DO. Percutaneous transluminal coro nary angioplasty: report of complications from the National Heart, Lung, and Blood Institute PTCA Registry. Circulation 1983;67:723-30.

18. Taylor RS, Higginson LAJ, Leopold KE. Dependence of the $\mathrm{XeCl}$ laser cut rate of plaque on the degree of calcification, laser fluence, and optical pulse duration. Lasers Surg Med 1990;10:414-9.

19. Izatt JA, Alhagli D, Britton M, Jubas JM, Itzkan I, Feld MS. Wavelength dependence of pulsed laser ablation of calcified tissue. Laser Surg Med 1991;11:238-49.

20. Karsch KR, Haase KK, Wehrmann M, Hassenstein S, Hanke $H$. Smooth muscle cell proliferation and restenosis after stand alone coronary excimer laser angioplasty. J Am Coll Cardiol $1991 ; 17: 991-4$

21. Sanborn TA. Early limitations of coronary excimer laser angioplasty. J Am Coll Cardiol 1991;17:995-6.

22. Preisack MB, Baumbach A, Athanasiadis A, Voelker W. Clinical outcome of acute vessel closure during coronary excimer laser angioplasty compared to conventional balloon angioplasty [Abstract]. Circulation 1991;84(suppl II):II-362.

23. King SB III. Role of new technology in balloon angioplasty. Circulation 1991;84:2574-9.

24. Brown BG, Bolson E, Frimer M, Dodge HT. Quantitative cornary arteringraphy. Circulation 1977;55:329-37.

25. Ellis SG, Vandormael MG, Cowley MJ, DiSciascio G, Deligonul U. Topol EJ, Bulle TM, and the Multivessel Angioplasty Prognosis Study Group. Coronary morphologic and clinical determinants of procedural outcome with angioplasty for multivessel coronary disease: implications for patient selection. Circulation 1990;8\%:1193-120\%.

26. Holmes D Jr, Myler R, Kent K, Williams DO, Faxon D, King S III, Bentivoglio L. Cowley M, Dorros G, Galichia J, Gosselin A, Al-Bassam M, Block $P$, Bourassa M, Leatherman L, Desvigne-Nickens $P$, Steenkiste A, Kelsey $S$, Detre K. National Heart, Lung, and Blood Institute Percutaneous Transluminal Coronary Angioplasty Registry as a standard for comparison of new devices: when should we use it, and what should we compare? Circulation 1991;84:1828-30. 